\title{
Assessment of several typical physical properties of reclaimed farmland filled with Yellow River sediment in Jining, China
}

\author{
Zhenqi Hu$^{1} \cdot$ Peijun Wang $^{2} \cdot$ Russell S. Yost $^{3} \cdot$ Fang Shao $^{1} \cdot$ Linghua Duo $^{1}$
}

Received: 27 September 2017/Revised: 19 February 2018/Accepted: 1 March 2018/Published online: 15 March 2018

(C) The Author(s) 2018

\begin{abstract}
Land subsidence caused by underground coal mining is one of the most prominent environment problems in China. The reclamation of mining subsidence land with Yellow River sediment was considered to be feasible, but its effectiveness needs to be verified. An integrated reclamation technology with Yellow River sediment was evaluated using a comparison of actual crop production soil profile analysis in Jining City, China. The results indicated that reconstructed soil profile of the reclaimed farmland was less effective in retaining water and in supporting plant growth than that of the unaltered farmland. Some measures are proposed, such as reducing the drainage velocity to allow sedimentation and retention of the clay and silt, changing the techniques of filling the Yellow River sediment and increasing the organic matter content in the soil layers to improve the capacity to retain water in the reclaimed farmland.
\end{abstract}

Keywords Yellow River sediment · Mining subsidence land · Land reclamation - Soil physical properties · Available water-holding capacity

\section{Introduction}

Coal is the most important energy source in China, accounting for about $70 \%$ of primary energy consumption (Hu et al. 2013). China is also the number one coal producer in the world, with coal outputs exceeding 3.65 billion tons in 2013, which accounted for $47.4 \%$ of the global production (BP Statistical Review of World Energy, 2014). Excavation of coal resources not only provides energy for the development of the national economy, but also causes damages to the land and ecology, such as occupation of

Zhenqi Hu

huzq1963@163.com

1 Institute of Land Reclamation and Ecological Restoration, China University of Mining and Technology (Beijing), D11 Xueyuan Road, Haidian District, Beijing 100083, China

2 College of Resources and Environment, Fujian Agricultural and Forestry University, Fuzhou, Fujian, China

3 Department of Tropical Plant and Soil Sciences, University of Hawai'i at Mānoa, Honolulu, HI 96822, USA land by coal wastes, land subsidence, landscape change, poisonous gas emission, and soil contamination. Land subsidence, the settling of land due to underground mining, seems to be one of the most prominent problems in China, because more than $90 \%$ of the coal output comes from underground mining, with thousands of underground long wall panels (Hu et al. 2013; Xiao et al. 2013). Seasonal or permanent water may enter the mining subsidence land prohibiting its use as productive farmland. It is estimated that the amount of subsidence area varies from 0.2 to $0.33 \mathrm{ha}$, per each $10000 \mathrm{t}$ of coal extracted. The subsidence area is expected to expand $7 \times 10^{4}$ ha annually throughout China (Hu et al. 2013). Thousands of hectares of productive farmland, therefore, loses the capacity of cultivation because of combination of extraction of a thick coal seam and already high groundwater table. Coal mine production has increased significantly during the past 30 years and exceeded 3.65 billion tons in 2013. It is predicted that mining production will continue to expand in the foreseeable future because of rapid economic growth in China. Consequently, the loss of land due to subsidence and other consequences of mining are sure to increase. 
China has a relatively small amount of cultivated land per capita. Thus, efficient utilization of land and strict protection of cultivated land have been the basic national policy of China since 1978. Nevertheless, cultivated land has still decreased significantly as a result of rapid economic growth. According to the Annual Bulletin issued by the Ministry of Land and Resource (MLR) in 2011, cultivated land decreased to 121.65 million hectares by the end of December 2011, with a decrease of 8.39 million hectares from 1996 to 2011. Thus, the Chinese government proposed to retain $1.2 \times 10^{8}$ ha of farmland as a base red line in 2007 to ensure national food security in 2020. How to increase the cultivated land at the stage of rapid economic growth in China? Reclamation of damaged land due to subsidence from coal mining operations may be a feasible and effective way.

Since the 1980s, China's land reclamation efforts have made considerable progress in restoring subsided land with different methods, and the engineering technology system of ecological restoration of mining subsidence land has been implemented. The current technology includes digging deep to fill shallow with hydraulic dredge pumps, land reclamation technology using towed scraper, land leveling, dredging and draining, and filling reclamation with coal wastes or fly ash or lake sludge, and so on (Hu et al. 2013; 2008). However, current reclamation methods do not solve the conflict between the large population and land shortage. The recovery percentage of cultivated land with the technology of digging deep to fill shallow is too low, and the shortage and potential contamination of the materials of filling reclamation method is too serious.

The Yellow River is one of the rivers with largest sediment concentration in the world (Zhang et al. 2004). The key governance technology of the Yellow River lies in sand control. To ensure the safety of the lower Yellow River, the government has invested huge amounts of money for dredging every year and thousands of hectares of land are occupied by the dredging sediment. It will be a good thing to satisfy both sides if not only the dredging sediment of Yellow River could be properly disposed, but also the shortage of filling materials of mining subsidence land could be solved. Considering the situation that some coal mines are near the Yellow River, reclamation of subsided land with river sediment may be a good way to reclaim damaged land due to mining subsidence. According to the conclusions of our research team (Wang et al. 2014), the texture type of Yellow River sediment is sand; the $\mathrm{pH}$ value of Yellow River sediment is slightly alkaline, electrical conductivity is very low while the contents of organic matter, total nitrogen, available nitrogen, total potassium, available potassium, total phosphorus and available phosphorus of Yellow River sediment are considered middle, low or very low. Contaminants such as $\mathrm{Cd}$ and $\mathrm{Hg}$ are not detected in the Yellow River sediment, and the contents of the heavy metals $\mathrm{Cr}, \mathrm{Cu}, \mathrm{Zn}, \mathrm{Pb}, \mathrm{Ni}$, and $\mathrm{As}$ are no more than the primary and secondary standard values of soil environmental quality standard of China (GB 15618-1995). Consequently, it seems feasible for Yellow River sediment to be used as reclamation material for mining subsidence land. However, the fertility and retention of both water and nutrients need to be improved. Improved methods of dredging sediment, sediment transportation, filling and drainage technology, and soil profile reconstruction are all needed in order to restore subsided land to productive farmland.

The objectives of this study are: (1) to introduce a flow chart of the reclamation of mining subsidence land with Yellow River sediment and the physical properties of a demonstration site in Jining City, Shandong Province, (2) to assess the feasibility and effectiveness of the integrated technology based on field crop growth and soil analysis of both the reclaimed and unaltered farmland; and (3) to propose the improvement of the reclamation technology.

\section{Materials and methods}

\subsection{Experimental site}

The experimental site was located in the west of Pengnali Village, Dalukou Town, Liangshan County, Jining City, Shandong Province (Fig. 1). This area is characterized by a semi-humid continental climate, with a mean annual temperature of $13.5^{\circ} \mathrm{C}$, a frost-free period of 205 days, and an annual precipitation of $601 \mathrm{~mm}$. According to the soil classification system of China, the soil originated from the alluvial deposits of Yellow River in this region belonged to fluvo-aquic soil (NSSO 1998; Zhang et al. 2001). The mining subsidence land was only $7.5 \mathrm{~km}$ away from the Yellow River comprising a total area of 48.7 ha. Seasonally stagnant water occurred in summer and autumn and as a result the subsided land could not be cultivated. The experimental site, shown in Fig. 1, was representative of the mining subsidence land while also providing some nearby land that was unaltered farmland.

\subsection{Reclamation procedures}

The reclamation engineering of mining subsidence land portion of the experiment with Yellow River sediment in the experimental site was started in February, 2011 and finished in July, 2011. The reclamation procedures were as follows.

Step 1: Stripping the surface soil and subsoil of the experimental site layer by layer. Before the start of filling reclamation of the experimental site, the seasonally 


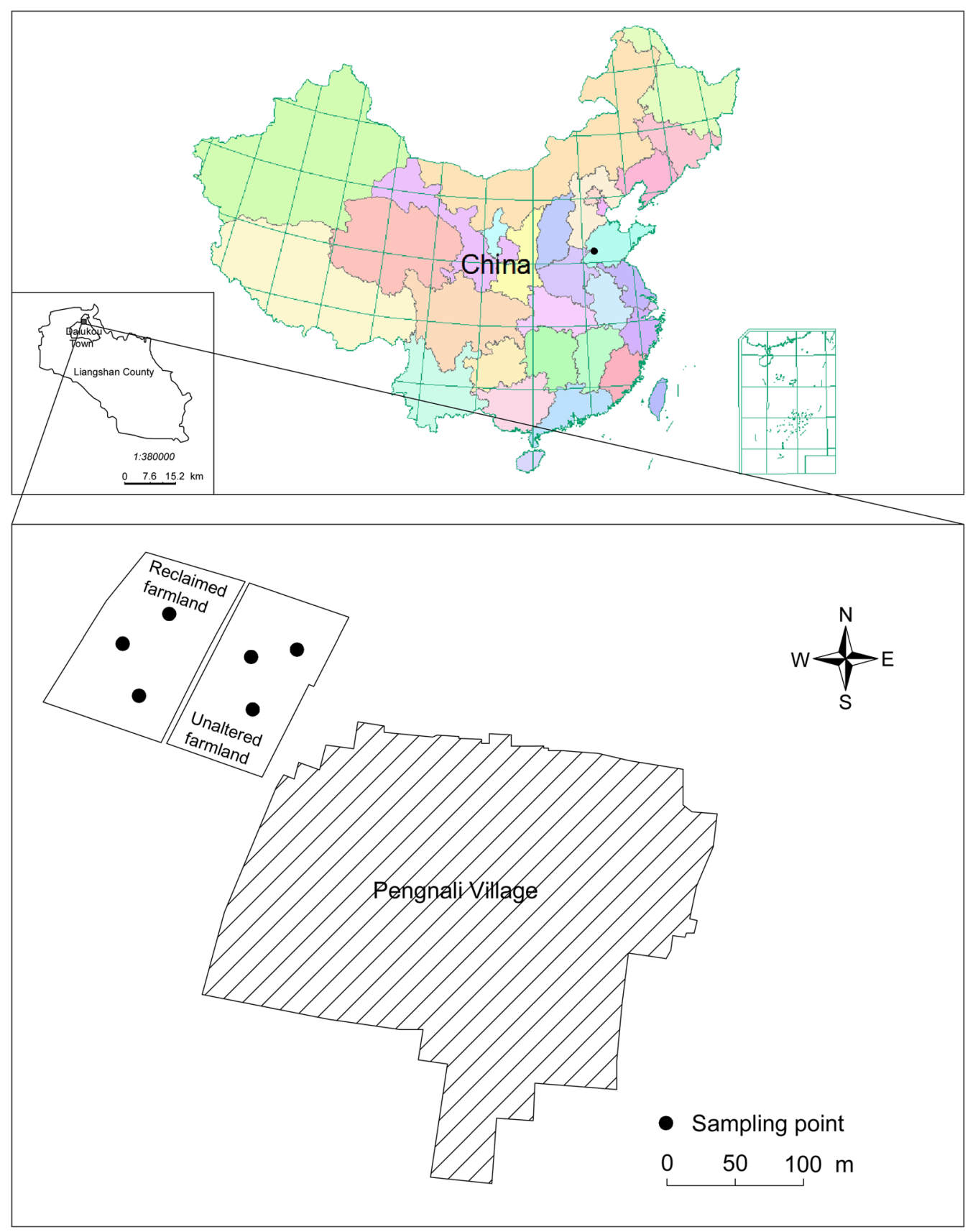

Fig. 1 Location of the experimental site

stagnant water needed to be drained away and the surface soil $(0-20 \mathrm{~cm})$ and subsoil $(20-50 \mathrm{~cm})$ were removed layer by layer with the excavator and placed nearby.

Step 2: Stirring and extracting the sediment from Yellow River with a dredge boat. A self-priming dredge boat with $185 \mathrm{~kW}$ submersible pump was used to stir and extract the sediment from Yellow River at the rate of 1000 cubic meters per hour of water-sediment mixture.

Step 3: Transporting the water-sediment mixture to the experimental site with pipeline. A pipe, $350 \mathrm{~mm}$ in inner diameter, was selected and at a distance of $7.5 \mathrm{~km}$ from the
Yellow River to the experimental site. One diesel generator pump with the power of 135 kilowatts was installed at the distance of $3.5 \mathrm{~km}$ from the suction dredger to ensure that the water-sediment mixture was transported to the experimental site with sufficient velocity to remain in suspension.

Step 4: Deposition of Yellow River sediment and drainage of excess water. The concentration of the watersediment mixture transported by the pipeline was about $400 \mathrm{~kg}$ of sediment per cubic meter of water-sediment mixture. The sediment was briefly allowed to settle in the 
experimental site and the excess water was discharged into a nearby river. At the edge of the reclaimed field, the depth of filled sediment ranged from 30 to $50 \mathrm{~cm}$ while the depth of sediment at the central part of the reclaimed field was about $100 \mathrm{~cm}$.

Step 5: Returning the surface soil and subsoil onto the sediment layer by layer. After the consolidation and leveling of the sediment, the stripped surface soil and subsoil were backfilled onto the sediment layer by layer with the bulldozer. The thickness of the surface soil layer plus subsoil layer was maintained at $50 \mathrm{~cm}$.

Step 6: Soil improvement of the reclaimed farmland. Soil improvement measures, such as the chemical fertilizer (847 kg of urea per hectare, $142.5 \mathrm{~kg}$ of $\mathrm{P}_{2} \mathrm{O}_{5}$ per hectare, $154.5 \mathrm{~kg}$ of $\mathrm{K}_{2} \mathrm{O}$ per hectare and $15 \mathrm{~kg}$ of $\mathrm{ZnSO}_{4} \cdot 7 \mathrm{H}_{2} \mathrm{O}$ per hectare) and $45 \mathrm{t}$ of farmyard manure per hectare, were applied each whole year to return the reclaimed land to high quality farmland.

\subsection{Sampling method}

Soil samples were collected from two sites on April 2th, 2013. One site was on the reclaimed farmland, which had been reclaimed about 2 years earlier, located west of Pengnali Village as shown in Fig. 1. A comparable, contrasting site (experimental plot) was selected on unaltered farmland, which was close to the reclaimed farmland. Three sampling points were located in the reclaimed and unaltered farmland, respectively. Sampling points were approximately $20 \mathrm{~m}$ apart within the experimental area of each treatment. One soil profile at each sampling point at each site was obtained. One sample (1 kg of soil) was collected from the surface soil layer $(0-20 \mathrm{~cm})$, subsoil layer $(20-50 \mathrm{~cm})$ and substratum $(50-80 \mathrm{~cm})$, respectively at each sampling point, and a total of 9 samples on each reclaimed and unaltered farmland were obtained, respectively.

\subsection{Analytical methods}

The particle size distribution of the samples was measured by a laser particle size analyzer Rise 2008, made by Jinan Rise Science and Technology Co., Ltd, China (Zhang et al. 2012). Pretreatment of the samples was in strict accordance with the steps that included: (1) leaching of the residual salt in the soil, (2) removal of organic matter with addition of $6 \%$ of $\mathrm{H}_{2} \mathrm{O}_{2}$ and calcium cement with addition of $0.2 \mathrm{~mol} \mathrm{~L}^{-1} \mathrm{HCl}$ (Yang et al. 2009), (3) neutralization of the samples and leaching removal of the excess calcium and chloride ions, and (4) the ultrasonic dispersion of the samples (Yang et al. 2009) and analysis (Zhang et al. 2012). The measurement range of the laser particle size analyzer was $0.02-1200 \mu \mathrm{m}$, the error of accuracy was less than $\pm 1 \%$ (National standard material: D50). The repetitive deviation was also less than $\pm 1 \%$ (National standard material: D50) (Zhang et al. 2012). Ten groups of data of each sample were collected after the particle size curve was stable and the average value of ten groups of data of each sample was selected as the final test value. Soil particle density was determined by use of pycnometer method (Zhao 1981; Lao 1988). Soil bulk density was measured by use of cutting ring method (Zhao 1981; Lao 1988). The calculation of the porosity was made through use of the equation:

Porosity $(\%)=\left(1-\frac{\text { Bulk density }}{\text { Particle density }}\right) \times 100$

Soil water content was measured by the oven drying technique (Zhao 1981; Lao 1988; Schmugge et al. 1980), that is a 15 or $20 \mathrm{~g}$ sample was collected in the field and quickly enclosed in an aluminum specimen box with a known weight $(m)$. The sample was weighed in the lab and its wet weight was recorded $\left(m_{1}\right)$, then it was placed in an oven at $105-110{ }^{\circ} \mathrm{C}$ for $6-8 \mathrm{~h}$ until a constant weight was obtained and its dry weight $\left(m_{2}\right)$ was recorded. Soil water content was calculated according to the following equation (Zhao 1981; Lao 1988):

Soil water content $(\%)=\frac{m_{1}-m_{2}}{m_{2}-m} \times 100$

The relationship between the soil water content and $\mathrm{pF}$ value of each soil was measured using the wide range $\mathrm{pF}$ meter (Model: DIK-3404) produced by Daiki Rika Kogyo Co., Ltd in Japan. This $\mathrm{pF}$ meter sets the $\mathrm{pF}$ value of the soil from $\mathrm{pF} 1.6$ to $\mathrm{pF} 4.2$ (water suction from 3.9 to $1500 \mathrm{kPa}$ ) by the pressure plate method. The volumetric water content was calculated from the mass water content by multiplying by each soil's bulk density, and the water suction was calculated from the $\mathrm{pF}$ value according to the conversion table in the instruction manual of the $\mathrm{pF}$ meter. The relationship between the soil volumetric water content and water suction of each soil was then obtained. The nonlinear regression equations of water characteristic curve for each soil layer of the reclaimed and unaltered farmlands were obtained using SigmaPlot 12.5 (Fig. 4a, b, c). The field capacity $\left(\mathrm{FC}_{\theta_{\mathrm{v}}}\right)$ and permanent wilting coefficient $\left(\mathrm{PWC}_{\theta_{\mathrm{v}}}\right)$ of each soil was estimated at its relative water potential using the nonlinear equation that best fit the data. Available water-holding capacity of each soil layer was calculated according to the following equation (Brady and Weil 2008):

Available water-holding capacity

$=\left(\mathrm{FC}_{\theta_{\mathrm{v}}}-\mathrm{PWC}_{\theta_{\mathrm{v}}}\right) \times$ plant root depth

The available water-holding capacity of total soil profile of the reclaimed and unaltered farmlands was the sum of 
Table 1 Particle size distribution of the reclaimed and unaltered farmlands according to the USDA system

\begin{tabular}{|c|c|c|c|c|c|c|c|c|c|}
\hline \multirow[t]{2}{*}{ Treatment } & \multicolumn{3}{|c|}{ Clay $(<0.002 \mathrm{~mm})$} & \multicolumn{3}{|c|}{ Silt $(0.002-0.05 \mathrm{~mm})$} & \multicolumn{3}{|c|}{ Sand $(0.05-2 \mathrm{~mm})$} \\
\hline & Mean $(\%)$ & Std $(\%)$ & $\mathrm{CV}(\%)$ & Mean $(\%)$ & Std $(\%)$ & $\mathrm{CV}(\%)$ & Mean (\%) & Std $(\%)$ & $\mathrm{CV}(\%)$ \\
\hline $\mathrm{SR}(0-20 \mathrm{~cm})$ & $34.42 a b c$ & 4.23 & 12.28 & $64.96 \mathrm{a}$ & 4.20 & 6.47 & $0.62 \mathrm{~b}$ & 0.21 & 33.53 \\
\hline $\mathrm{SR}(20-50 \mathrm{~cm})$ & $24.55 \mathrm{bc}$ & 15.49 & 63.11 & $64.16 \mathrm{a}$ & 1.45 & 2.26 & $11.29 \mathrm{~b}$ & 14.54 & 128.74 \\
\hline $\mathrm{SR}(50-80 \mathrm{~cm})$ & $0.00 \mathrm{c}$ & 0 & NA & $2.91 \mathrm{~b}$ & 3.78 & 129.76 & $97.09 \mathrm{a}$ & 3.78 & 3.89 \\
\hline CK $(0-20 \mathrm{~cm})$ & $72.61 \mathrm{a}$ & 9.75 & 13.43 & $27.39 \mathrm{ab}$ & 9.75 & 35.60 & $0.00 \mathrm{~b}$ & 0 & NA \\
\hline CK $(20-50 \mathrm{~cm})$ & $60.00 \mathrm{ab}$ & 26.09 & 43.49 & $39.96 \mathrm{ab}$ & 26.04 & 65.18 & $0.04 \mathrm{~b}$ & 0.06 & 141.42 \\
\hline CK $(50-80 \mathrm{~cm})$ & $54.13 \mathrm{ab}$ & 28.02 & 51.77 & $45.64 \mathrm{a}$ & 27.86 & 61.05 & $0.23 \mathrm{~b}$ & 0.18 & 76.05 \\
\hline
\end{tabular}

Notes SR refers to the reclaimed farmland filled with Yellow River sediment and CK refers to the unaltered farmland. The means with the different letters in the same columns are significantly different at the 0.05 level. NA is not applicable

the available water-holding capacity of the surface soil $(0-20 \mathrm{~cm})$, subsoil $(20-50 \mathrm{~cm})$ and the substratum soil $(50-80 \mathrm{~cm})$, respectively.

Excel 2007 was used to calculate the standard deviation and coefficient of variation, SAS 8.1 was used for analysis of variance and SigmaPlot 12.5 was used for graphing and nonlinear regression.

\section{Results and discussion}

\subsection{Soil texture}

According to the USDA system, the particle size distribution of the reclaimed farmland filled with Yellow River sediment and unaltered farmland is presented in Table 1. The texture types varied from different soil layers of the reclaimed and unaltered farmlands. The clay contents of the surface soil layer $(0-20 \mathrm{~cm})$ and subsoil layer $(20-50 \mathrm{~cm})$ of the reclaimed farmland were $34.42 \%$ and $24.55 \%$, respectively, while those of the unaltered farmland were $72.61 \%$ and $60.00 \%$, respectively. The results of analysis of variance indicate that there was no significant difference between the clay contents of the two sampling sites at the 0.05 level. The silt contents of the surface soil layer $(0-20 \mathrm{~cm})$ and subsoil layer $(20-50 \mathrm{~cm})$ of the reclaimed farmland were $64.96 \%$ and $64.16 \%$, respectively, which had no significant difference (at the 0.05 level) with those of the unaltered farmland, whose silt contents were $27.39 \%$ and $39.96 \%$, respectively. However, as for the substratum $(50-80 \mathrm{~cm})$, the contents of clay, silt and sand of the reclaimed farmland were $0 \%, 2.91 \%$ and $97.09 \%$, respectively, while those of the unaltered farmland were $54.13 \%, 45.64 \%$ and $0.23 \%$, respectively, which significantly differed from those of the reclaimed farmland at the 0.05 level. In addition, there were relatively larger coefficients of variation with the clay and sand contents of the subsoil layer $(20-50 \mathrm{~cm})$ and the silt content of the substratum $(50-80 \mathrm{~cm})$ of the reclaimed farmland, and also with the contents of clay, silt and sand of the subsoil layer $(20-50 \mathrm{~cm})$ and substratum $(50-80 \mathrm{~cm})$ of the unaltered farmland. According to the USDA system of textural classification (Brady and Weil 2008), the soil textures of the surface soil layer $(0-20 \mathrm{~cm})$, subsoil layer $(20-50 \mathrm{~cm})$ and substratum $(50-80 \mathrm{~cm})$ of the reclaimed farmland were silty clay loam, silt loam and sand textural categories, respectively, while those of the unaltered farmland were clay, clay and silty clay categories, respectively. In short, the unaltered farmland had fine-textured soil, while the reclaimed farmland had relatively coarse-textured soil.

The Yellow River sediment mainly originated from the Loess Plateau in its middle and upper reaches (Qin et al. 2007). Not surprisingly the particle size distribution of the deposit sediment and suspended sediment in Yellow River was similar to that of loess in the middle and upper reaches of Yellow River (Hu et al. 2004). Three size fractions, clay $(<0.002 \mathrm{~mm})$, silt $(0.002-0.05 \mathrm{~mm})$ and very fine sand $(0.05-0.1 \mathrm{~mm})$ of suspended sediment accounted for $89 \%-$ $96.3 \%$ of the sediment. The fine sand $(0.10-0.25 \mathrm{~mm})$, medium sand $(0.25-0.50 \mathrm{~mm})$, coarse sand $(0.50-1.0 \mathrm{~mm})$ and very coarse sand $(1.0-2.0 \mathrm{~mm})$, only accounted for $3.7 \%-11 \%$, indicating that the particle size of suspended sediment was fine and with a trend of becoming finer from the middle reaches to the lower reaches of Yellow River (Hu et al. 2004; Sun et al. 2010). However, it was found that most of the sediment deposited in the lower Yellow River channel was larger than $0.05 \mathrm{~mm}$ (Qin et al. 2007) and accounted for about $70 \%-72 \%$ of the total deposition (Qin et al. 2007). The article (Xu et al. 2009) indicated that $76.61 \%$ of the sediment greater than $0.05 \mathrm{~mm}$ and $97.68 \%$ of the sediment that was greater than $0.10 \mathrm{~mm}$ would be deposited in the riverbed. The particle size of more than $90 \%$ of the sediment that comprised the substratum of the reclaimed farmland ranged from 0.05 to $0.25 \mathrm{~mm}$ and belonged to fine sand or very fine sand, according to the U.S.D.A. system of textural classification. That the 
sediment applied to the reclaimed substratum was so coarse may be due to the rapid application and deposition of the transported water-sediment mixture. Keeping in mind that the sedimentation times for particles of 2,5 and $20 \mu$ diameter requires 427, 68 and $4.27 \mathrm{~min}$ to descend and be deposited to a depth of $10 \mathrm{~cm}$ (Day 1965). As a result, the rapid drainage of excess water from the outfall of the reclamation strip almost certainly removed all of the clay and silt-sized particles. As a result only the sand $(>20 \mu)$ (according to the system of textural classification of International Society of Soil Science) remained in place and comprised the substratum.

The high level of clay in the unaltered farmland may be the result of long term irrigation with Yellow River water, which contained much suspended clay and silt. With the addition and sedimentation of the clay and silt in the farmland year by year, the particle size of surface soil and subsoil may have become finer and finer. The large coefficient of variation of amount of clay, silt and sand of the subsoil layer $(20-50 \mathrm{~cm})$ and substratum $(50-80 \mathrm{~cm})$ of the unaltered farmland may relate to the fact that much of the soil parent material of the land in this region was sediment resulting from the periodic disastrous floods of Yellow River (Qin et al. 2007; Shao et al. 1989; Feng 1991). According to the soil classification system of China, the soil originated from the alluvial deposits of Yellow River in this region belonged to fluvo-aquic soil and the soil texture of the fluvo-aquic soil was known to be highly variable, including sand, loam, clay loam and clay (NSSO 1998; Zhang et al. 2001). The reason may be that the sandy and silty sediment was usually deposited near the levee burst and along the both sides of fast-flowing water, forming zonal sand dunes and hills. Far away from the levee burst and on both sides of the rapids, the flood flow fanned out, leaving more loamy and silty sediment was dominated. Far from the riverbed and shallow depressions the water velocity was reduced and became stagnant in lake depressions and as a result the particle size was finer and soil textures belonged to clay loam or clay. Due to multiple bursts and river diversions, various types of sediment was repeatedly accumulated in the different landform parts of the plain, resulting in sharp differences in texture of the same soil layer (NSSO 1998). In addition, the particle size of the suspended sediment in Yellow River flood water was different due to the variations in precipitation and human activities (Xu 1999). In the Yellow River alluvial plain, the content of sand $(0.02-2.0 \mathrm{~mm})$ in sandy sediment was as high as $90.37 \%$; the total content of silt $(0.002-0.02 \mathrm{~mm})$ and sand (0.02-2.0 $\mathrm{mm}$ ) ranged from $79.07 \%$ to $91.11 \%$ in loamy sediment and the content of clay $(<0.002 \mathrm{~mm})$ in clay sediment was as high as $39.71 \%$ (NSSO 1998). However, the substratum sediment of the reclaimed farmland was taken from the Yellow River shoal, whose particle size was coarse ( $\mathrm{Xu}$ et al. 2009; Chen et al. 2000). As a result of the overlying soil thickness of many parts of the reclaimed farmland was about $30 \mathrm{~cm}$, thus with deep plowing year by year, the overlying soil layer and substratum sediment layer was probably mixed resulting in the particle size of the overlying soil of the reclaimed farmland to become coarser than that of the unaltered farmland. This may have been the reason for the large coefficient of variation with the clay and sand contents of the subsoil layer $(20-50 \mathrm{~cm})$ and the silt content of the substratum $(50-80 \mathrm{~cm})$ of the reclaimed farmland.

\subsection{Soil particle density, bulk density and porosity}

Soil particle density, bulk density and porosity of the reclaimed and unaltered farmlands are shown in Fig. 2. As indicated in Fig. 2a, there was no significant difference in the soil particle densities between the reclaimed and unaltered farmlands at the 0.05 level.

As shown in Fig. 2b, there was also no significant difference in the soil bulk densities between the reclaimed and unaltered farmlands at the 0.05 level. Bulk density is an indicator of density of the soil that may be affected by compaction or distribution of particles. In some cases it may relate to how well plant roots are able to extend into the soil. The soil textures of the surface soil layer $(0-20 \mathrm{~cm})$, subsoil layer $(20-50 \mathrm{~cm})$ and substratum $(50-80 \mathrm{~cm})$ of the reclaimed farmland were silty clay loam, silt loam and sand, respectively, whose corresponding values of restricting root growth were above $1.65,1.75$ and $1.80 \mathrm{~g} / \mathrm{cm}^{3}$, respectively, and these values for the unaltered farmland were all above $1.47 \mathrm{~g} / \mathrm{cm}^{3}$ (Arshad et al. 1996). The soil bulk densities of the reclaimed and unaltered farmlands in this study were all lower than the limiting values.

The results, as shown in Fig. 2c, there was significant difference in the soil porosities of the substratum $(50-80 \mathrm{~cm})$ between these two sampling sites at the 0.05 level, but no significant difference (at the 0.05 level) in those of the surface soil layer $(0-20 \mathrm{~cm})$ and subsoil layer $(20-50 \mathrm{~cm})$ between these two sampling sites. The soil porosities of the unaltered farmland decreased gradually with increasing soil depth. However, there was a decrease and then a sharp increase in size in the coarse-textured substratum $(50-80 \mathrm{~cm})$ of the reclaimed farmland.

Development of structure results in the formation of pore spaces between aggregates, resulting in an increase in the porosity and a decrease in the bulk density (Foth 1990). Since structural development tends to be greatest in the surface soil, it is at this level in the profile that porosity is usually the greatest and bulk density the lowest (Hausenbuiller 1985). Lower porosities and higher bulk densities in the subsoil are usually associated with a relatively low 

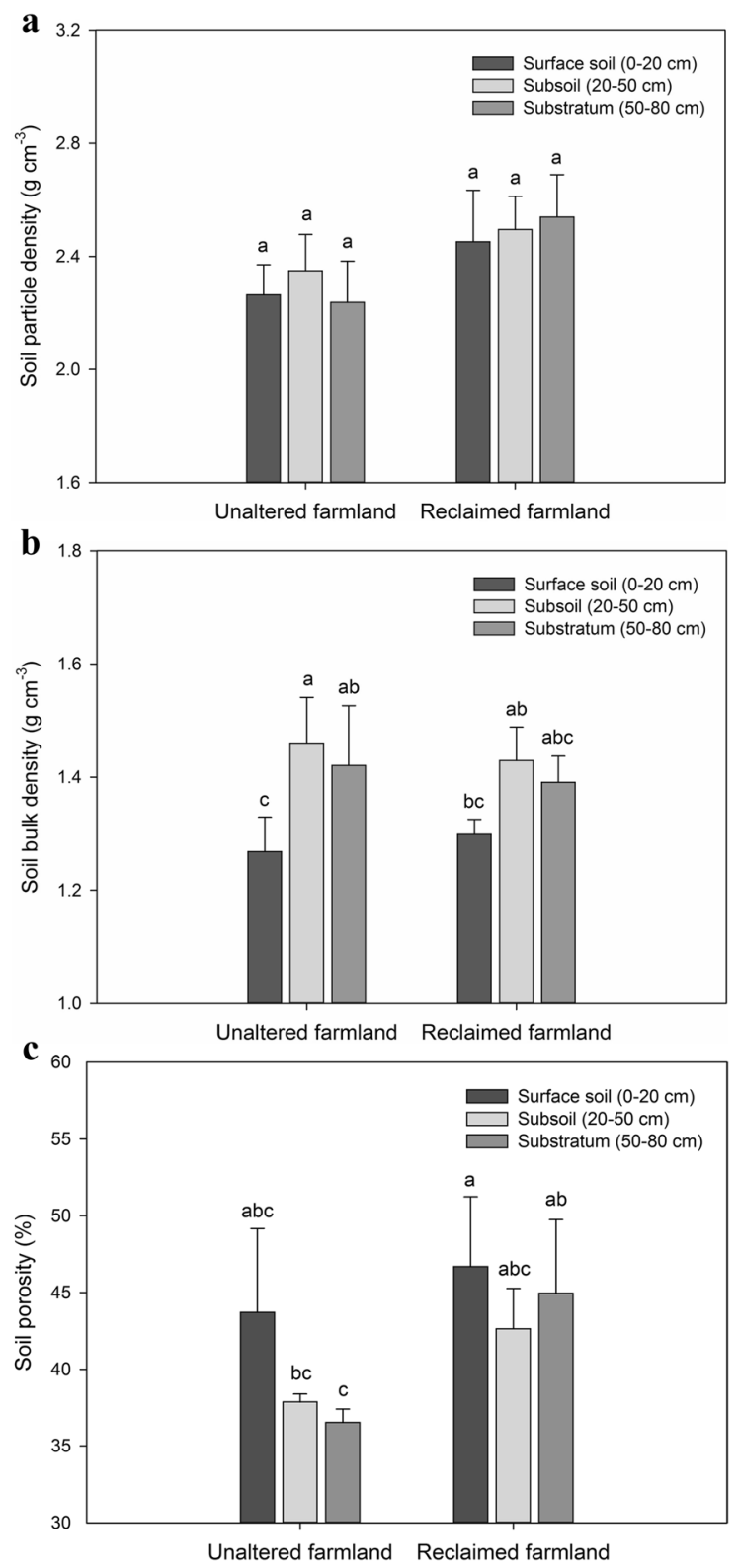

Fig. 2 Soil particle density, bulk density and porosity of the reclaimed and unaltered farmlands. The means with the different letters in the same columns are significantly different at the 0.05 level. a Soil particle density, b soil bulk density, c soil porosity

degree of structural development and a higher state of compaction due to the weight of the overlying soil (Foth 1990). The trend of gradual decrease of soil porosity of the unaltered farmland with increasing soil depth observed in this study was consistent with the above references (Foth 1990; Hausenbuiller 1985). As for the reclaimed farmland, the soil porosities presented a trend of first decrease and then increase. The reason may be that the soil bulk density of the substratum $(50-80 \mathrm{~cm})$ was lower than that of the subsoil layer $(20-50 \mathrm{~cm})$, while the particle density of the substratum $(50-80 \mathrm{~cm})$ was higher than that of the subsoil layer $(20-50 \mathrm{~cm})$, resulting in the soil porosity of the substratum $(50-80 \mathrm{~cm})$ was higher than that of the subsoil layer $(20-50 \mathrm{~cm})$.

\subsection{Soil water content and plant available water- holding capacity}

In order to assess and manage soil water status, the field soil water needs to be measured. The soil water content of the reclaimed and unaltered farmlands are shown in Fig. 3. There was significant difference in the soil water content of the subsoil layer $(20-50 \mathrm{~cm})$ and substratum $(50-80 \mathrm{~cm})$ between these two sampling sites at the 0.05 level, while there was no significant difference (at the 0.05 level) for the surface soil layer $(0-20 \mathrm{~cm})$. The soil water content of the reclaimed farmland decreased with increasing soil depth, while the unaltered farmland tended to increase.

The relationship between the volumetric water content and water suction of surface soil, subsoil and substratum soil of the reclaimed and unaltered farmlands is shown in Fig. 4 and the nonlinear regression equations used to smooth the water characteristic curve measurements of each soil layer are shown in Table 2.

Figure $4 \mathrm{a}, \mathrm{b}$ indicate that the volumetric water content of the surface soil and subsoil of the reclaimed farmland was comparable with that of the unaltered farmland when the water suction was below $10 \mathrm{kPa}$, but that the volumetric water content of the reclaimed farmland was less than that of the unaltered farmland when the water suction was greater than $10 \mathrm{kPa}$. As shown in Fig. $4 \mathrm{c}$, the volumetric water content of the substratum soil of the reclaimed farmland was comparable with that of the unaltered farmland when the water suction was below $5 \mathrm{kPa}$. However, when the water suction was beyond $5 \mathrm{kPa}$, the volumetric water content of the reclaimed farmland decreased very quickly to a low level and was less than that of the

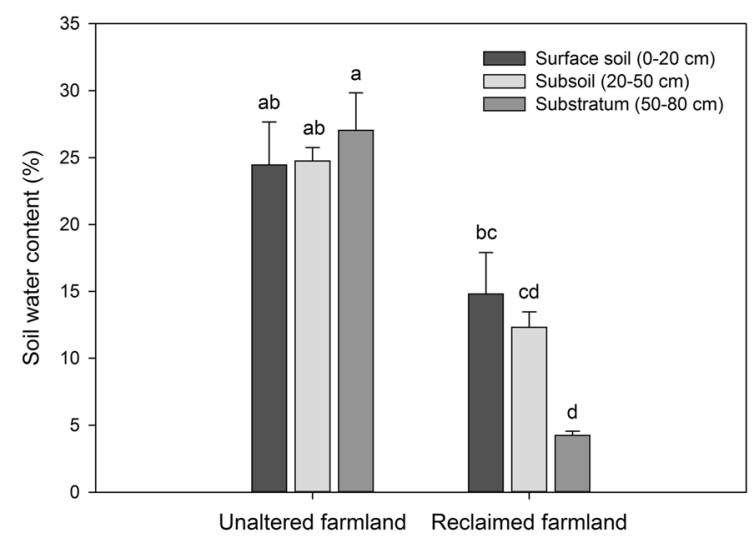

Fig. 3 Soil water content of the reclaimed and unaltered farmlands. The means with the different letters in the same columns are significantly different at the 0.05 level 


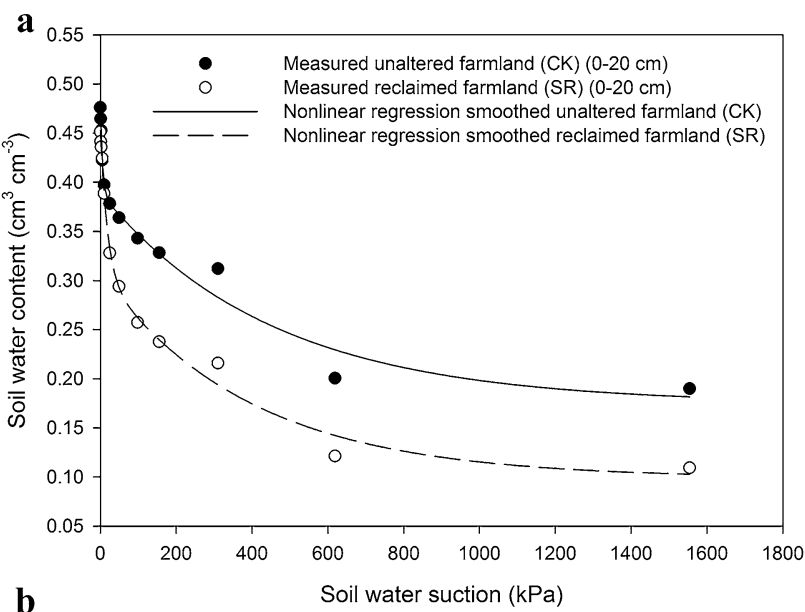

b
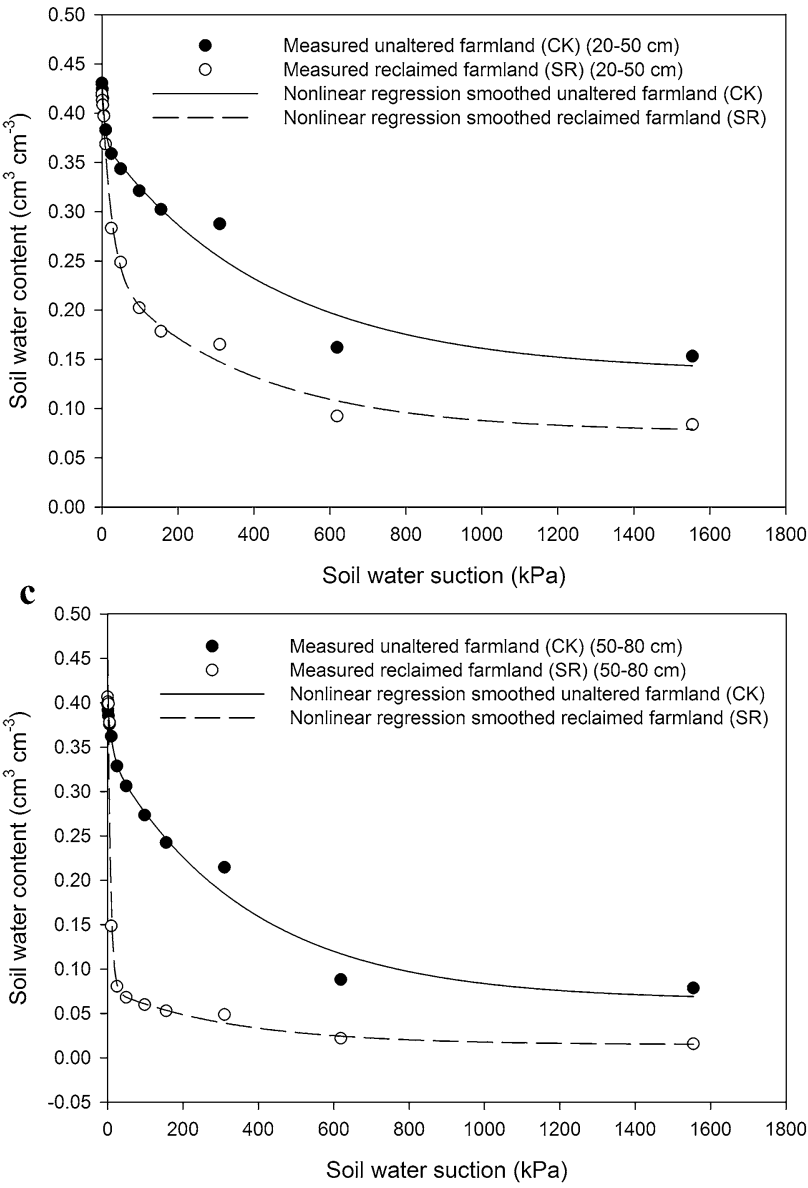

Fig. 4 Relationship between the volumetric water content and water suction of surface soil, subsoil and substratum soil of the reclaimed and unaltered farmlands. a Surface soil $(0-20 \mathrm{~cm})$, b subsoil $(20-50 \mathrm{~cm})$, c substratum $(50-80 \mathrm{~cm})$

unaltered farmland. For most soils, field capacity was estimated at the water potential of -10 to $-33 \mathrm{kPa}$ (Brady and Weil 2008). The volumetric water content of the surface soil and subsoil of the reclaimed farmland began to be less than that of the unaltered farmland after the field capacity was reached, while the volumetric water content of the substratum soil of the reclaimed farmland started to be less than that of the unaltered farmland before the field capacity was reached, indicating that the substratum soil (sediment) of the reclaimed farmland drained water very quickly and had low capacity to retain water. There was difference in the shape and range in soil water characteristic curve of the two kinds of sampling sites shown in Fig. 4, which may be due to that there was more clay content in the surface soil, subsoil and substratum soil of the unaltered farmland than that of the reclaimed farmland, respectively, as shown in Table 1 . The greater the clay content, in general, the greater the water retention at any particular suction, and the more gradual the slope of the curve (Hillel 1998).

For most soils, the permanent wilting coefficient was estimated at the water potential of $-1500 \mathrm{kPa}$ (Brady and Weil 2008). According to the smoothed water characteristic curves shown in Table 2, the field capacity of each soil layer was estimated using both -10 and $-33 \mathrm{kPa}$, then the available water-holding capacity of each soil layer was calculated and the estimates are shown in Table 3. The results indicate that the estimated soil profile available water-holding capacity of the reclaimed farmland was only $56.42 \%-69.42 \%$ of that of the unaltered farmland. A probable result of relatively low content of soil water was that the plant population of wheat in the reclaimed farmland (Fig. 5a) was much less than that of the unaltered farmland (Fig. 5b). In many parts of the reclaimed farmland, the wheat seed did not germinate. The field investigation immediately before wheat harvest indicated that the wheat root of the reclaimed farmland was also lower than that of the unaltered farmland (Table 3), and the wheat yield of the reclaimed farmland was only about one half of that of the unaltered farmland (Hu et al. 2015).

\subsection{Comprehensive analysis of soil physical properties of reclaimed farmland filled with Yellow River sediment}

Although much subsided land can be reclaimed using Yellow River sediment with the technology used in this demonstration site, and it may be a solution to solve the conflict between large human population and land shortage in long term, but it still has many disadvantages. Firstly, the soil profile reconstructed with the technology used at present retains much smaller amounts of plant available water and does not support plant and crop production as well as the unaltered farmland. With the current rapid drainage of the water from the pumped sediment it is clear that most if not all of the silt and clay in the sediment is lost to the rapid drainage. The loss of clay and silt and the resulting extremely high content of sand leave a growth media, which has low capacity to retain water in the range 
Table 2 Nonlinear regression equations of water characteristic curve of each soil layer of the reclaimed and unaltered farmlands

\begin{tabular}{|c|c|c|c|c|}
\hline Soil & Equations & $R^{2}$ & Adjusted- $R^{2}$ & $P$ \\
\hline SR $(0-20 \mathrm{~cm})$ & $\theta_{v}=0.0988+0.1454 \mathrm{e}^{-0.0543 \psi}+0.2087 \mathrm{e}^{-0.0025 \psi}$ & 0.9934 & 0.9896 & $<0.0001$ \\
\hline SR $(20-50 \mathrm{~cm})$ & $\theta_{v}=0.0764+0.1866 \mathrm{e}^{-0.0404 \psi}+0.1614 \mathrm{e}^{-0.0026 \psi}$ & 0.9944 & 0.9911 & $<0.0001$ \\
\hline SR $(50-80 \mathrm{~cm})$ & $\theta_{v}=0.0147+0.3820 \mathrm{e}^{-0.1449 \psi}+0.0618 \mathrm{e}^{-0.0030 \psi}$ & 0.9706 & 0.9538 & $<0.0001$ \\
\hline CK $(0-20 \mathrm{~cm})$ & $\theta_{v}=0.1747+0.0889 \mathrm{e}^{-0.1845 \psi}+0.2147 \mathrm{e}^{-0.0022 \psi}$ & 0.9813 & 0.9706 & $<0.0001$ \\
\hline CK $(20-50 \mathrm{~cm})$ & $\theta_{v}=0.1365+0.0589 \mathrm{e}^{-0.1434 \psi}+0.2359 \mathrm{e}^{-0.0023 \psi}$ & 0.9755 & 0.9616 & $<0.0001$ \\
\hline CK $(50-80 \mathrm{~cm})$ & $\theta_{v}=0.0648+0.0564 \mathrm{e}^{-0.0803 \psi}+0.2761 \mathrm{e}^{-0.0027 \psi}$ & 0.9865 & 0.9788 & $<0.0001$ \\
\hline
\end{tabular}

Notes $\theta_{v}$ means soil volumetric water content, $\psi$ means soil water suction

Table 3 Soil profile available water-holding capacity of the reclaimed and unaltered farmlands

\begin{tabular}{|c|c|c|c|c|c|c|}
\hline Soil & $\begin{array}{l}\text { Wheat root } \\
\text { depth }(\mathrm{cm})\end{array}$ & $\begin{array}{l}\text { Field } \\
\text { capacity }\left(\theta_{v}\right) \\
(\%)^{[I]}\end{array}$ & $\begin{array}{l}\text { Field } \\
\text { capacity }\left(\theta_{v}\right) \\
(\%)^{[\mathrm{II}]}\end{array}$ & $\begin{array}{l}\text { Permanent wilting } \\
\text { coefficient }\left(\theta_{v}\right) \\
(\%)^{[I I I]}\end{array}$ & $\begin{array}{l}\text { Available water holding- } \\
\text { capacity }\left(\text { AWHC) }(\mathrm{cm})^{[1]}\right.\end{array}$ & $\begin{array}{l}\text { Available water holding- } \\
\text { capacity }\left(\text { AWHC) }(\mathrm{cm})^{[I I]}\right.\end{array}$ \\
\hline $\mathrm{SR}(0-20 \mathrm{~cm})$ & 20 & 38.68 & 31.52 & 10.37 & 5.66 & 4.23 \\
\hline $\begin{array}{l}\text { SR } \\
\qquad(20-50 \mathrm{~cm})\end{array}$ & 29.8 & 35.82 & 27.37 & 7.97 & 8.30 & 5.78 \\
\hline $\begin{array}{l}\text { SR } \\
\qquad(50-80 \mathrm{~cm})\end{array}$ & 0 & 16.44 & 7.39 & 1.54 & 0 & 0 \\
\hline $\begin{array}{l}\text { Total } \\
\qquad(0-80 \mathrm{~cm})\end{array}$ & 49.8 & & & & 13.96 & 10.01 \\
\hline $\begin{array}{l}\text { CK } \\
\qquad(0-20 \mathrm{~cm})\end{array}$ & 20 & 39.88 & 37.46 & 18.26 & 4.32 & 3.84 \\
\hline $\begin{array}{l}\text { CK } \\
\qquad(20-50 \mathrm{~cm})\end{array}$ & 30 & 38.11 & 35.57 & 14.40 & 7.11 & 6.35 \\
\hline $\begin{array}{l}\text { CK } \\
\qquad(50-80 \mathrm{~cm})\end{array}$ & 30 & 35.88 & 32.13 & 6.96 & 8.68 & 7.55 \\
\hline $\begin{array}{l}\text { Total } \\
\qquad(0-80 \mathrm{~cm})\end{array}$ & 80 & & & & 20.11 & 17.74 \\
\hline
\end{tabular}

Notes ${ }^{[\mathrm{I}]}$ Field capacity and available water-holding capacity were estimated at soil water potential of $-10 \mathrm{kPa}$ (soil water suction of $10 \mathrm{kPa}$ ). ${ }^{[\mathrm{II}]}$ Field capacity and available water-holding capacity were estimated at soil water potential of $-33 \mathrm{kPa}$ (soil water suction of $33 \mathrm{kPa}$ ).

${ }^{[I I I]}$ Permanent wilting coefficient was estimated at soil water potential of $-1500 \mathrm{kPa}$ (soil water suction of $1500 \mathrm{kPa}$ )

needed by plants (Foth 1990; Huang and Xu 2010). Secondly, the size of the reclamation strip is usually large, which results in the elevation of the filling sediment is non uniform, generating significantly shallower topsoil in the central part of the reclamation strip. Uniformly thicker topsoil is likely to improve plant and crop growth.

Some improvement measures of the technology can be considered as follows. The first is reducing the drainage velocity to better retain the clay and silt, so the geotextiles can be used to retain the clay and silt and drain the water. The second is changing the technical process of filling reclamation with Yellow River sediment to reconstruct an improved soil profile. Firstly, Yellow River sediment is filled to the reclamation strip at the depth of about $1 \mathrm{~m}$ from the ground surface; then about 15-20 cm of stripped clay soil is backfilled; thirdly sediment is continuously filled at the designed elevation and then backfilled with surface soil in layers. The soil profile reconstructed in this method would better retain water than the traditional method that doesn't retain a clayey soil layer between the overlying soil layer and substratum sediment layer. The third is increasing the organic matter content in the overlying soil layer to increase the capacity to hold water. It is suggested that green manure plants can be grown and incorporated for the first 3 years and the wheat straw also added to the soil after harvest.

\section{Conclusions}

A field of 48.7 ha of mining subsidence land was reclaimed with Yellow River sediment since July, 2011 and planted to crops for three times. This indicated that it's feasible to reclaim subsided land with Yellow River sediment. Crop 

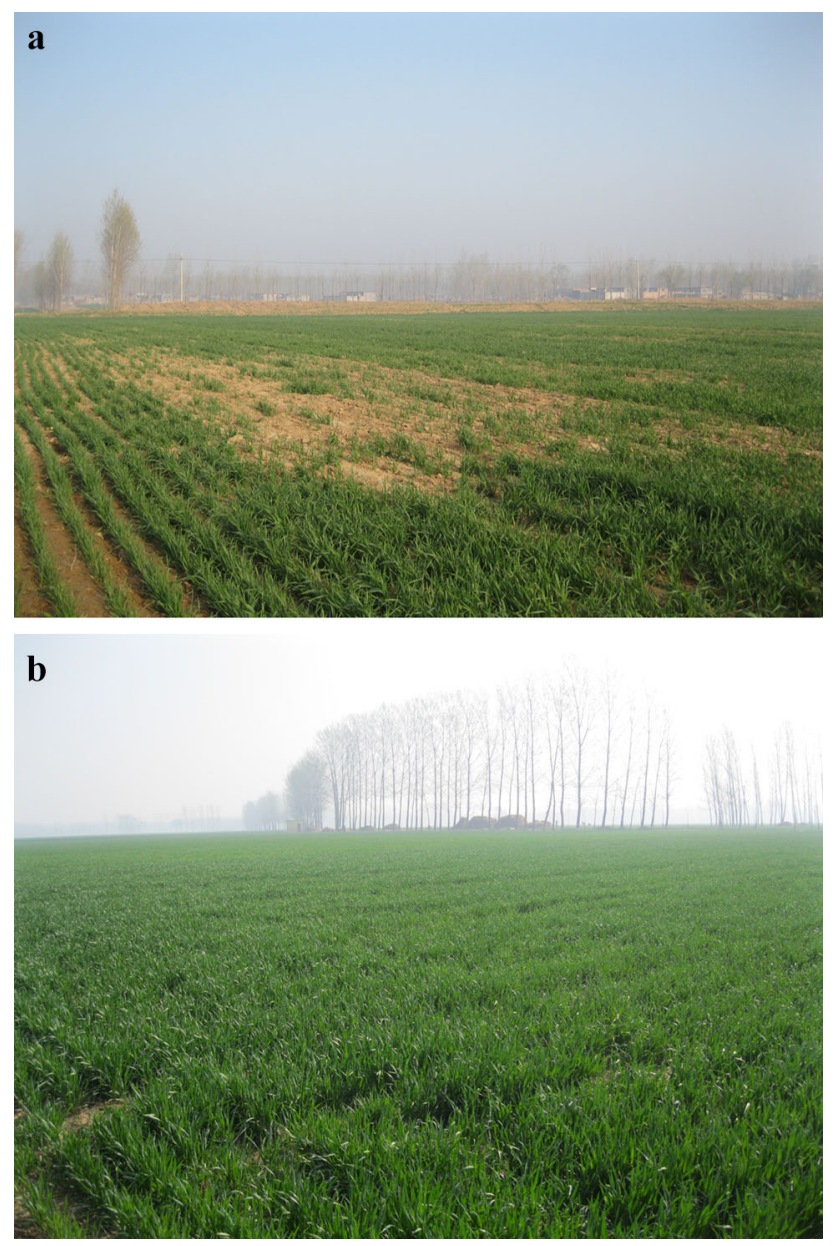

Fig. 5 Wheat growth of the reclaimed and unaltered farmlands. a Reclaimed farmland, $\mathbf{b}$ unaltered farmland

productivity, however remained depressed in the reclaimed farmland.

In short, the particle size of each soil layer of the reclaimed farmland was coarser than that of the corresponding layer of the unaltered farmland. At the surface soil layer $(0-20 \mathrm{~cm})$ and subsoil layer $(20-50 \mathrm{~cm})$, there was no significant difference in the soil particle densities, bulk densities and porosities between these two sampling sites at the 0.05 level. There was also no significant difference (at the 0.05 level) in the soil water content of the surface soil layer $(0-20 \mathrm{~cm})$ between these two kinds of soil profiles. However, there was significant difference in the soil porosities of the substratum $(50-80 \mathrm{~cm})$ and the soil water content of the subsoil layer $(20-50 \mathrm{~cm})$ and substratum $(50-80 \mathrm{~cm})$ between these two soil profiles at the 0.05 level. The substratum soil (sediment) of the reclaimed farmland drained water very quickly and was less effective in retaining plant available water. Wheat grew less well on the reclaimed farmland than on the unaltered farmland.
There are some disadvantages of the technology as implemented at present. Firstly, the reclaimed farmland has a suboptimal performance for retaining water and plant growth. Secondly, the size of the reclamation strip is usually large, which results in an uneven and occasionally shallow surface soil that isn't sufficiently deep to support plant growth. Some improved measures such as reducing the drainage velocity to retain more clay and silt with the geotextiles, changing the process of filling reclamation with Yellow River sediment and increasing the organic matter content in the overlying soil layer with the addition of the crop straw and residue of the green manure plants are proposed.

Acknowledgements This research was supported by National Key Technology Research and Development Program (2012BAC04B03) during the Twelfth Five-Year Plan Period and National Natural Science Foundation of China (Grant No. 41771542). The authors thank Mr. De-Shui Cai in Land Regulation Center of Jining City, Hai-Tao Zheng in Land Resources Bureau of Liangshan County, Ya-kai Chen and Zhi-yong Qiao in China University of Mining and Technology (Beijing) for their assistance for sampling soils.

Open Access This article is distributed under the terms of the Creative Commons Attribution 4.0 International License (http://crea tivecommons.org/licenses/by/4.0/), which permits unrestricted use, distribution, and reproduction in any medium, provided you give appropriate credit to the original author(s) and the source, provide a link to the Creative Commons license, and indicate if changes were made.

\section{References}

Arshad MA, Lowery B, Grossman B (1996) Physical tests for monitoring soil quality. In: Doran JW, Jones AJ (eds) Methods for assessing soil quality. Soil Science Society of America Special Publication 49, SSSA, Madison, pp 123-141

BP's Economics Team (2014) BP statistical review of world energy, June 2014, BP p.l.c. http://www.bp.com/content/dam/bp/pdf/ Energy-economics/statistical-review-2014/BP-statistical-reviewof-world-energy-2014-full-report.pdf. Accessed 19 June 2014

Brady NC, Weil RR (2008) The nature and properties of soils, 14th edn. Pearson Education Inc, New Jersey

Chen JS, Hong S, Wang LX, Wang FY (2000) Geo-chemical parameters of river particulate in eastern China. Acta Geogr Sin $55: 417-427$

Day PR (1965) Particle fractionation and particle-size analysis. In: Black CA (ed) Methods of soil analysis. Part 1. Physical and mineralogical properties, including statistics of measurement and sampling. American Society of Agronomy, Soil Science Society of America, Madison, pp 545-567

Feng DK (1991) Human activities and plains geomorphology evolution of the lower reaches of the Yellow River region during different historical period. Yellow River 22:58-60

Foth HD (1990) Fundamentals of soil science, 8th edn. Wiley, New York

Hausenbuiller RL (1985) Soil science: principles and practices, 3rd edn. Wm. C. Brown Company Publishers, Iowa, p 1985

Hillel D (1998) Environmental soil physics: fundamentals, applications, and environmental considerations. Academic Press, Cambridge 
Hu GH, Zhao PL, Xiao XQ (2004) Sediment characteristics of Yellow River and their influence on water environment. Water Resour Hydropower Eng 35:17-20

Hu ZQ, Bian ZF, Cheng S, Zhao YL, Yang F, Zheng LQ, Chen QJ, Chen SH, Yang XH, Fu MC, Li J (2008) Land reclamation and ecological reconstruction. China University of Mining and Technology Press, Xuzhou

Hu ZQ, Xiao W, Wang PJ, Zhao YL (2013) Concurrent mining and reclamation for underground coal mining. J China Coal Soc 38:301-307

Hu ZQ, Wang PJ, Shao F (2015) Technique for filling reclamation of mining subsidence land with Yellow River sediment. Trans Chin Soc Agric Eng (Trans CSAE) 31:288-295

Huang CY, Xu JM (2010) Soil science, 3rd edn. China Agriculture Press, Beijing

Lao JC (1988) Handbook of agricultural soil analysis. China Agriculture Press, Beijing

National Soil Survey Office (NSSO) (1998) Soils of China. China Agriculture Press, Beijing

Qin MZ, Richard JH, Yuan ZJ, Mark JW, Sun B (2007) The effects of sediment-laden waters on irrigated lands along the lower Yellow River in China. J Environ Manag 85:858-865

Schmugge TJ, Jackson TJ, Mckim HL (1980) Survey of methods for soil moisture determination. Water Resour Res 16:961-979

Shao SX, Guo SQ, Han SH (1989) The landscape structure characteristics and evolution of Huanghuaihai plain. Acta Geogr Sin 44:314-322

Sun JH, Chai Y, Wang GL, Zhang G, Li J (2010) Review on effects of sediment on the water quality of the Yellow River. J Sedim Res $1: 72-80$
Wang PJ, Hu ZQ, Shao F, Jiang ZD, Qiao ZY, Liu DW, Chen YK (2014) Feasibility analysis of Yellow River sediment used as the filling reclamation material of mining subsidence land. J China Coal Soc 39:1133-1139

Xiao W, Hu ZQ, Li TQ, Wang FJ, Li H, Liu KK (2013) Dynamic subsidence simulation and land reclamation efficiency analysis of surface ground above mining block. Min Sci Technol $41: 126-128$

Xu JX (1999) Grain-size characteristics of suspended sediment in the Yellow River, China. Catena 38:243-263

Xu JX, Hu CH, Chen JG (2009) The influence of the sediment with different particle size on the deposition in lower reaches of Yellow River and the significance on the management of Yellow River. Sci China Technol Sci 39:310-317

Yang JL, Zhang GL, Li DC, Pan JH (2009) Relationships of soil particle size distribution between sieve-pipette and laser diffraction methods. Acta Pedol Sin 46:772-780

Zhang FR, Wang QB, Ye MB, Guan X, Xu H, Wu KN, Zhou YC, Jia SH, Pan GX (2001) Soil geography. China Agriculture Press, Beijing

Zhang ZK, Wang SM, Yang XD, Jiang FC, Shen J, Li XS (2004) Evidence of a geological event and environmental change in the catchment area of the Yellow River at $0.15 \mathrm{Ma}$. Quatern Int 117:35-40

Zhang YD, Wang JP, Wei MJ, Zhang B, Zhou R (2012) Correlation between the content of different grain size and magnetic susceptibility in core Changping. Acta Sedimentol Sin 30:572-579

Zhao QG (1981) Analysis method of soil physical properties. Science Press, Beijing 